\title{
Comparison Between Different Endodontic Irrigating Protocols In Smear Layer Removal From Radicular Dentin
}

\author{
Ramona Vlad, MD \\ Monika Kovacs, Lecturer, $\mathrm{MD}, \mathrm{PhD}$ \\ Dragos Sita, Assistant Lecturer, MD \\ Mihai Pop, Lecturer, MD, PhD \\ Faculty of Dental Medicine, \\ University of Medicine and Pharmacy Tirgu Mures, Romania
}

doi: 10.19044/esj.2016.v12n15p38 URL:http://dx.doi.org/10.19044/esj.2016.v12n15p38

\begin{abstract}
The aim of our study was to measure the cleaning efficiency of irrigating solutions used during endodontic treatment regarding smear layer removal from the root canal dentin walls. Ethylenediaminotetraacetic acid (EDTA) 17\%, citric acid (CA) 10\% and sodium hypochlorite (NaOCl) 2,5\% solutions were tested as final irrigating solutions. The study was conducted on extracted teeth, divided in four groups according to the irrigation protocol used. The specimens were analyzed by scanning electron microscopy and the amount of smear layer present at apical, middle and coronal level was recorded, based on a scoring system. Data were statistically analyzed using Kruskal-Wallis and Friedman test and the level of significance was set at $\mathrm{p}<0.05$. In the coronal and middle segments of dental roots we noticed no statistically significant difference between EDTA and CA in smear layer removing capacity. Final irrigation with 17\% EDTA proved to be more efficient than $10 \% \mathrm{CA}$ and $2,5 \% \mathrm{NaOCl}$ in smear layer removal at apical level of the root canal, with $\mathrm{p}<0.05(\mathrm{p}=0.042)$, which is an important area for disinfection in endodontic treatment.
\end{abstract}

Keywords: Chelating agents, smear layer, scanning electron microscope, radicular dentin

\section{Introduction}

The main purpose in endodontic therapy is to remove infected dental pulp and debris by chemical and mechanical preparation, as the clinical success is based on proper instrumentation, disinfection and hermetic filling 
of the root canal. During this process, a special complex of organic and inorganic debris is formed on the radicular dentin surface as a result of endodontic treatment, named smear layer [Haapasalo, Shen, Qian and Gao, 2010 and Violich \& Chandler, 2010]. The irrigating protocols used for cleaning contain sodium hypochlorite $(\mathrm{NaOCl})$ solution 2, 5-5,25\% combined with a chelating agent, but the best sequence of solutions is still a reason of debate and controversy in the scientific literature [Zand et al., 2010]. The use of $\mathrm{NaOCl} 5,25 \%$ and EDTA 17\% had been proposed as an excellent irrigation protocol, which effectively removes debris and smearlayer [Mello, Kammerer, Yoshimoto, Macedo and Antoniazzi, 2010].

It is an artificial aminoacid with a $\mathrm{pH} \mathrm{7,} \mathrm{biocompatible} \mathrm{and} \mathrm{with} \mathrm{a}$ reduced antibacterial effect, based on the inhibiting effect on bacterial growth by chelating with metallic ions used in their metabolisms [Pitoni, Fiquerido, Aranjo and Souza, 2011, and Dai et. al., 2011]. EDTA can be used in combination with a surfactant, in order to remove calcifications from the pulp chamber or obliterated root canals, allowing proper cleaning and shaping. Another chelating agent is citric acid that has been suggested to exert a good capacity of smear layer removal [Dai et. al., 2011]. The most common is a $10 \%$ solution maintained in contact with dentin for $2-3$ minutes.

The aim of our study was to compare the effectiveness of EDTA, $\mathrm{NaOCl}$ and $\mathrm{CA}$ in smear layer removal from infected root canals after different endodontic irrigating protocols.

\section{Material and methods}

Ethical approval was taken before starting this study in which we used forty human freshly extracted necrotic teeth. All teeth were stored in formalin solution for 1-2 days and instrumented according to the step-back technique using K-files (Dentsply-Maillefer, Ballaigues, Switzerland) up to \# 40, with $\mathrm{NaOCl} 5,25 \%$ irrigation after each file, followed by $5 \mathrm{ml}$ of saline solution. The teeth were divided in 4 study groups: Group I - EDTA 17\%, Group II - citric acid 10\%, Group III - NaOCl 5, 25\% and Group IV control, irrigation with saline solution. For the SEM evaluation, longitudinal grooves were made on the surface of the crown and root using a diamond disk at low speed, without penetrating the canal. The roots were split in half with a sharp blade and were coded according to the protocol used and the specimens were examined using a SEM (Tesla BS 340, Brno, Czech Republic) at x1000 and x750 magnification at the coronal, middle and apical thirds, based on a graded scale from 1-3 (1 - complete smear layer removal, open dentin tubules, 2 - moderate smear layer, partially opened tubules, 3 dentin surface completely covered with smear layer) in order to assess the quality of smear layer removal. Photomicrographs of the examined areas were taken and evaluated by two independent observers in a double-blind 
manner. Statistical analysis was carried out with the Statistical Package for Social Sciences (SPSS) version 16.0 for Windows. Non parametric data of smear layer scores were presented as a percentage distribution and the mean ranks were calculated for each root section. The Kruskal-Wallis test was used to compare between final irrigation solutions at each section between study groups and Friedman test was used to compare between root canal thirds at each group. The level of significance was set at $\mathrm{p}<0.05$.

\section{Results}

According to Kruskal -Wallis test there were no statistically significant differences between EDTA and CA except for the apical thirds of the root canal, where CA proved to be more efficient in smear layer removing ability with $\mathrm{p}<0.05(\mathrm{p}=0.042)$. The mean scores of smear layer removal for the control and study groups are presented and listed in Fig. 1-2 and Table. These show the ability of chelating agents to remove debris efficiently in the coronal and middle thirds of the root canal.

Table 1. Mean scores of smear layer removal from the radicular dentin wall

\begin{tabular}{|c|c|c|c|c|}
\hline $\begin{array}{c}\text { Study group/ } \\
\text { Root area }\end{array}$ & $\begin{array}{c}\text { Coronal third } \\
\text { Mean (+/-SD) }\end{array}$ & $\begin{array}{c}\text { Middle third } \\
\text { Mean (+/-SD) }\end{array}$ & $\begin{array}{c}\text { Apical third } \\
\text { Mean }(+/-S D)\end{array}$ & $\mathrm{p}$-value \\
\hline Control (saline) & $3.0+/-0.0$ & $3.0+/-0.0$ & $3.0+/-0.0$ & $\mathrm{P}=1(\mathrm{p}>0.05)$ \\
\hline EDTA & $1.3+/-0.68$ & $1.4+/-0.56$ & $2.6+/-0.48$ & $\mathrm{P}=0.008(\mathrm{p}<0.01)$ \\
\hline CA & $1.2+/-0.80$ & $1.1+/-0.88$ & $1.78+/-0.24$ & $\mathrm{P}=0.006(\mathrm{p}<0.01)$ \\
\hline Chlorhexidine & $3.0+/-0.0$ & $3.0+/-0.0$ & $3.0+/-0.0$ & $\mathrm{P}=1(\mathrm{p}>0.05)$ \\
\hline
\end{tabular}

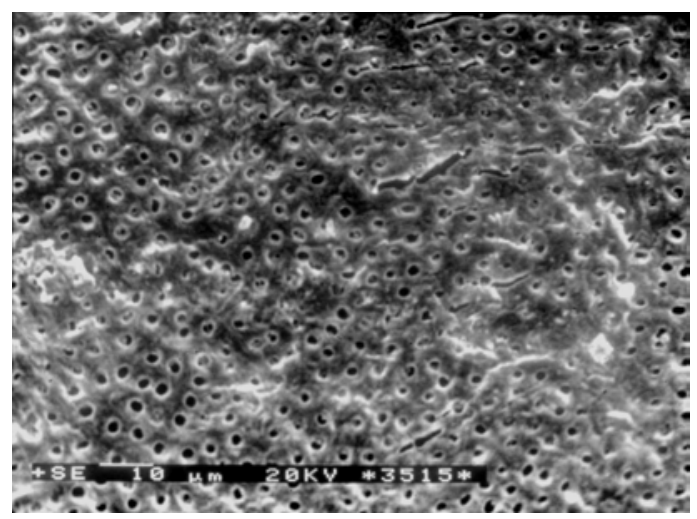

Fig.1. Photomicrograph showing complete removal of the smear layer from the radicular dentine, CA group, (score 1). 


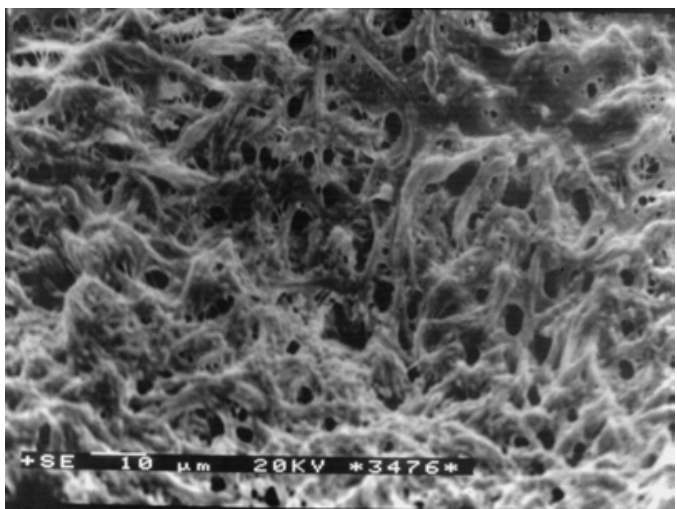

Fig. 2. Image from CHX group, with smear layer present on the dentin wall (score 3).

In the apical part, CA proved to have better cleaning properties compared to EDTA and CHX. The Friedman test had shown statistically significant differences within EDTA and CA groups regarding the degree of smear layer removal from canal sections, with a $\mathrm{p}<0.05(\mathrm{p}=0.008$ and $\mathrm{p}=0.006$ respectively). We recorded also a significant erosion of dentinal tubules in samples irrigated with EDTA, disclosing an important decalcifying effect of this solution.

\section{Discussion}

Root canal instrumentation produces a layer of organic and inorganic material called smear layer that may contain bacteria and their by-products. In endodontic treatment it has many disadvantages as it prevents the penetration of endodontic medicaments into dentinal tubules and disrupts the seal between the dentin walls and root filling, conditions that may lead to treatment failure [Violich \& Chandler, 2010, and Monea, Stoica, Bechir, Burcea and Pangica, 2016]. Cleaning of endodontic system is extremely important and $\mathrm{NaOCl} 5,25 \%$ solution is considered to be the gold standard in endodontic irrigating protocols due to its very good tissue dissolving effect; at the same time, it has been suggested to degrade micromechanical characteristics of dentin. Furthermore, it is toxic to apical tissue and has no effect on the inorganic component of the smear-layer. $\mathrm{NaOCl} \mathrm{5,25 \%}$ solution promotes the formation of smear layer during instrumentation and the use of a chelating agent facilitates the smear layer removal [Liu, Kuah and Chen, 2007]. Another important endodontic irrigant is CHX, a cationic polybisguanide which can be used due to the antimicrobial activity and its unique property called substantivity. Until now, using chelating agents was done mostly by irrigation with EDTA, which has been tested in different concentrations and for different time periods [Di Lenarda, Candenaro and Sbaizero, 2000, Monea, Beresescu, Stoica and Stefanescu, 2016, and Cobankara, Erdogan and Hanurcu, 2011]. The disadvantages noticed were 
lack efficiency in the apical area and dentinal erosion in the middle and coronal part of the root. Previous studies had shown that there is no significant difference between CA and EDTA regarding the capacity of smear layer removal, but both disclosed a limited antibacterial effect [Kuruvilla et. al., 2015, Kumar et. al., 2015]. Spano et. al. (2009) examined smear layer removal with different solutions and found that EDTA and CA had comparable effectiveness. Our results showed that 5, 25\% $\mathrm{NaOCl}$ and $2 \%$ CHX did not promote an adequate cleaning of radicular dentin, with a great amount of smear layer present. Previous studies had demonstrated that CHX 2\% solution could be an effective endodontic irrigant; it could maintain the canal free of microorganisms but few studied had shown its cleaning capacity. The present study was carried out on extracted teeth and therefore the results do not allow a definite conclusion regarding the effects of chelating solutions used in situ. The presence of blood and tissue fragments, together with other variables may influence the action of these chemical agents under use in the root canal system. Therefore, more long term clinical studies are necessary in order to confirm these results and to evaluate their relevance to dental endodontic practice.

\section{Conclusion}

The apical part of root canal imposes a special attention during irrigation as the borderline between safety and effectiveness is particularly important in this area. Final irrigation of the root canal with 10\% CA is more efficient than $17 \%$ EDTA in smear layer removal at apical level, which represents the most important area for disinfection. The chelating agents used, especially EDTA, exhibited an important decalcifying effect, therefore the risk of dentin erosion should be taken into consideration.

\section{References:}

Haapasalo M., Shen Y., Qian W., Gao Y. Irrigation in endodontics. Dent Clin North Am; 2010, 54: 291-312.

Violich D.R., Chandler N.P. The smear layer in endodontics - a review. Int Endod J; 2010; 43: 2-15.

Zand, V., Lotfi, M., Rahimi, S., Mokktari, H., Kazemi, A., Sakhamanesh, V. A comparative scanning electron microscopic investigation of the smear layer after the use of sodium hypochlorite gel and solutions forms as root canal irrigants. J Endod. 36(7), 2010, p. 1234-1237.doi: 10.1016/j.joen 2010.02.033.

Mello, I., Kammerer, B.A., Yoshimoto, D., Macedo, M.C., Antoniazzi, J.H. Influence of final rinse technique on ability of ethylenediaminotetraaminoacetic acid of removing smear layer. J Endod. 36, 2010, p. 512-514. 
Pitoni, C.M., Fiquerido, M.C., Aranjo, F.B., Souza, M.A. Ethylenediaminetetraacetic acid and citric acid solutions for smear layer removal in primary tooth root canals. J Dent Child. 78(3), 2011, p. 131-137.

Dai, L., Khechen, K., Khan, S., Gillen, B., Loushine, B.A., Wimmer, C.E. The effect of QMix, an experimental antibacterial root canal irrigant on removal of canal wall smear layer and debris. J Endod. 37, 2011, p.80-84.

Monea M., Stoica A., Bechir E.S., Burcea A., Pangica A.M.In vitro sealing ability of Mineral Trioxide aggregate. Rev. Materiale Plastice, 2016; 53(1): 6-8.

Liu, J.N., Kuah, H.G., Chen, N.N. Effect of EDTA with and without surfactants or ultrasonics on removal of smear layer. J Endod. 33(24), 2007, p. $472-475$.

Di Lenarda, R., Candenaro, M., Sbaizero, O. Effectiveness of 1 mol L-1 citric acid and 15\% EDTA irrigation on smear layer removal. Int Endod J.33, 2000, p. 46-52.

Monea M., Beresescu G., Stoica A., Stefanescu T. Biocompatibility of calcium hydroxide -based root canal sealers: A histological study. Key Engineering Materials, 2016; 695: 243-246.

Cobankara, F.K., Erdogan, H., Hanurcu, M. Effects of chelating agents on the mineral content of root canal dentin. Oral Surg Oral Med Oral Pathol Oral Radiol Endod. 112, 2011, p. 49-54.

Kuruvilla, A., Jaganath, B.M., Krishnegouda, S.C., Romachandra, P.K., Johns, D.A., Abraham, A. A comparative evaluation of smear layer removal by using edta, etidronic acid and maleic acid as root canal irrigants: An in vitro scanning electron microscopic study. J Conserv Dent. 18(3), 2015, p. 247-251. doi: 10.4103/0972-0707.157266.

Kumar, P., Prasad, N., Darawade, A., Bhagat, S.K., Narayana, N., Darawade, $P$. The effect of four commonly used root canal irrigants on the removal of smear layer: An in vitro scanning electron microscopic study. J Int Oral Health. 7(9), 2015, p. 88-93.

Spano, J.C., Silva, R.G., Guedes, D.F., Sousa-Neto, M.D., Estrela, C., Pecora, J.D. Atomic absorption spectrometry and scanning electron microscopy evaluation of concentration of calcium ions and smear layer removal with root canal chelators. J Endod. 35, 2009, p. 727-730. 